SECCIÓN ABIERTA 

REVISTA DE DERECHO UNED, NÚM. 21, 2017

\title{
EL CARÁCTER JURISDICCIONAL DE LOS TRIBUNALES DE RESOLUCIÓN DE CONFLICTOS CONTRACTUALES CONFORME A LA JURISPRUDENCIA COMUNITARIA
}

\author{
THE JURISDICTIONAL CHARACTER OF THE PUBLIC \\ PROCUREMENT REVIEW COURTS ACCORDING TO \\ COMMUNITY CASE-LAW
}

JACINTO J. MARABEL

Doctor en Derecho. Comisión Jurídica de Extremadura

Resumen: Durante muchos años, la Unión Europea exigió al Reino de España articular una serie de medidas tendentes a garantizar los procedimientos de recurso en materia de adjudicación de contratos públicos. La materia tiene una importancia crucial en las políticas europeas y su impacto económico llega a alcanzar la quinta parte del PIB del conjunto de los Estados miembros. Por esta razón, se hizo necesaria la creación de órganos independientes con competencia en la resolución de este tipo de conflictos que velaran por el principio de libre concurrencia. El Tribunal de Justicia de la Unión Europea considera que la naturaleza y funciones de tipo de órganos, que a partir del Tribunal Central de Recursos Contractuales se han extendido a gran parte de las Comunidades Autónomas, son asimilables a las de los órganos jurisdiccionales.

Palabras clave: Contratos del sector público, recurso especial, Tribunal Administrativo de Recursos Contractuales, Comunidades Autónomas.

Abstract: For many years, the European Union demanded the Kingdom of Spain to articulate a series of measures to ensure the review procedures in the field of public procurement. The matter is of crucial 
importance in European policies and their economic impact can reach a fifth of the GDP of all the Member States. For this reason, the creation of independent bodies with competence in the resolution of such conflicts that shall ensure the principle of free competition was necessary. The Court of Justice of the European Union considered that the nature and functions of type of organs, which starting from the Public Procurement Review Central Administrative Court have been extended to much of the Autonomous Communities, are similar to the justice courts.

Keywords: Public-sector contracts, special review, Public Procurement Review Administrative Court, Autonomus Communities.

Recepción original: 20/06/2017

Aceptación original: 27/10/2017

Sumario: I. Introducción. II. Antecedentes normativos. III. Composición y carácter de los órganos de resolución de conflictos contractuales. IV. Conclusiones.

\section{INTRODUCCIÓN}

A nadie escapa que la normativa en materia de contratación pública está sometida a una constante evolución y transformación. Tampoco que, en la actualidad, su regulación obedece en gran medida a las directrices que promueven la contratación pública en el ámbito comunitario. La importancia y el carácter privilegiado que se otorga desde Bruselas a las políticas que inciden en esta materia radica, entre otros extremos, en el impacto económico que supone el flujo comercial dentro espacio Schengen y que, según Flueger Tejero, llega a suponer en torno al 19\% del PIB del conjunto de los Estados miembros ${ }^{1}$. Quizás en este contexto quepa entender, aunque no justificar, que el vigente Texto Refundido de la Ley de Contratos del Sector Público (TRLCSP) aprobado mediante Real Decreto Legislativo 3/2011, de 14 de noviembre, haya sufrido más de una docena de modificaciones hasta la fecha².

${ }^{1}$ Pflueger Tejero, Eduardo. «Aspectos más destacados de las nuevas Directivas sobre adjudicación de contratos de concesión y sobre contratación pública. Directiva 2014/23/UE y Directiva 2014/24/UE, del Parlamento Europeo y del Consejo». Revista de la Función Consultiva, núm. 21. Consejo Jurídico Consultivo de la Comunidad Valenciana, 2014; págs. 132-133.

${ }^{2}$ Sin contar con que, al poco de su publicación, ya hubo que corregir algunos errores advertidos en el texto a través del BOE de 3 de febrero de 2012, la Ley 17/2012, de 27 de diciembre, de Presupuestos Generales del Estado para el año 2013 añadió un nuevo apartado a la Disposición Adicional Vigesimoctava. Con posterioridad, conocería sucesivas modificaciones a través del Real Decreto-ley 4/2013, de 22 de febrero, de medidas de apoyo al emprendedor y de estímulo del crecimien- 
Con anterioridad al mismo, la Ley 34/2010, de 5 de agosto, abordó una importante reforma en materia de contratación pública en nuestro país ${ }^{3}$. La modificación vino obligada a raíz de la Sentencia del Tribunal de Justicia de la Unión Europea (STJUE), Sala Segunda, de 3 de abril de 2008, en la que se condenaba al Reino de España por el incumplimiento de las obligaciones derivadas del artículo 2.1, en sus apartados a) y b), de la Directiva 89/665/CEE del Consejo, de 21 de diciembre de 1989, relativa a la coordinación de la disposiciones legales, reglamentarias y administrativas referentes a la aplicación de los procedimientos de recurso en materia de adjudicación de contratos públicos de suministro y de obras, en la modificación operada a través de la Directiva 92/50/CEE del Consejo, de 18 de junio de 1992.

Tal y como reconocía el Preámbulo de la Ley 34/2010, de 5 de agosto, se trataba de resolver algunas cuestiones esenciales en aras a garantizar los derechos de los interesados que preveía la normativa

to y de la creación de empleo; Ley 8/2013, de 26 de junio, de rehabilitación, regeneración y renovación urbanas; Ley 10/2013, de 24 de julio, por la que se incorporaron al ordenamiento jurídico español las Directivas 2010/84/UE del Parlamento Europeo y del Consejo, de 15 de diciembre de 2010, sobre farmacovigilancia, y 2011/62/UE del Parlamento Europeo y del Consejo, de 8 de junio de 2011, sobre prevención de la entrada de medicamentos falsificados en la cadena de suministro legal, y se modifica la Ley 29/2006, de 26 de julio, de garantías y uso racional de los medicamentos y productos sanitarios; Ley 11/2013, de 26 de julio, de medidas de apoyo al emprendedor y de estímulo del crecimiento y de la creación de empleo; Ley 14/2013, de 27 de septiembre, de Emprendedores; Ley 20/2013, de 9 de diciembre, de garantía de la unidad de mercado; Ley 25/2013, de 27 de diciembre, de Impulso de la factura electrónica; Real Decreto-ley 1/2014, de 24 de enero, de reforma en materia de infraestructuras y transporte, y otras medidas económicas; Ley 2/2015, de 30 de marzo, desindexación de la economía española; Ley 25/2015, de 28 de julio, de segunda oportunidad; Ley 31/2015, de 9 de septiembre, por la que se modifica y actualiza la normativa en materia de autoempleo y se adoptan medidas de fomento y promoción del trabajo autónomo y de la economía social; Ley 40/2015, de 1 de octubre, de Régimen Jurídico del Sector Público; y Real Decretoley 10/2015, de 11 de septiembre, por el que se Concede créditos extraordinarios y suplementos de crédito en el presupuesto del Estado y se adoptan otras medidas en materia de empleo público y de estímulo de la economía. Deberán tenerse en cuenta, además, las puntuales órdenes del Ministerio de Hacienda y Administraciones Públicas, que fueron actualizando las cuantías de los contratos de servicios comprendidos en el apartado 1.b) del artículo 40 TRLCSP, Órdenes EHA/3479/2011, de 19 de diciembre, HAP/2425/2013, de 23 de diciembre y HAP/2846/2015, de 29 de diciembre.

${ }^{3}$ Vid. Ley 34/2010, de 5 de agosto de, modificación de las Leyes 30/2007, de 30 de octubre, de Contratos del Sector Público, 31/2007, de 30 de octubre, sobre Procedimientos de Contratación en los Sectores del Agua, la Energía, los Transportes y los Servicios Postales, y 29/1998, de 13 de julio, reguladora de la Jurisdicción Contencioso-Administrativa, para adaptación a la normativa comunitaria de las dos primeras. BOE de 9 de agosto de 2010. 
comunitaria. Entre ellas y en lo que atañe a este trabajo, la atribución de la competencia para la resolución de los recursos especiales en materia de contratación a un órgano objetivo, imparcial e independiente que, en el ámbito de la Administración General del Estado fue conferida al Tribunal Administrativo Central de Recursos Contractuales y, con las peculiaridades que en seguimiento se referirán, con el tiempo se han ido descentralizando en órganos asimilados en algunas Comunidades Autónomas.

Aunque estos últimos órganos han sido constituidos hace relativamente muy poco tiempo, ya cuentan en su haber con un número nada desdeñable de resoluciones de notable cualificación jurídica que sin duda serán objeto de examen y referencia obligada en los próximos años. Por nuestra parte y como quiera que dicho propósito excedería con mucho el marco del presente trabajo, a continuación trataremos de ceñirnos someramente a las circunstancias que antepusieron su creación, a las competencias atribuidas y la labor desarrollada desde su puesta en funcionamiento, así como los requisitos que configuran su carácter jurisdiccional tal y como previene la normativa comunitaria y ratifica su jurisprudencia.

\section{ANTECEDENTES NORMATIVOS}

En la última década del siglo pasado la Unión Europea tomó conciencia de la escasa operatividad del conjunto de medidas articuladas hasta entonces, para garantizar la transparencia de los acuerdos de preparación y adjudicación de contratos públicos. De este modo, la citada Directiva 89/665/CEE fue aprobada para tratar de paliar el efecto disuasorio que, para algunas empresas comunitarias, tenía la ausencia o insuficiencia de recursos en materia contractual existentes en algunos Estados miembros, entre ellos España, así como de medidas provisionales encaminadas a suspender los procedimientos de adjudicación o la ejecución de decisiones adoptadas por los poderes adjudicadores. En este sentido, la normativa obligaba a los Estados miembros a promover medidas que, en lo relativo al artículo 2.1 infringido, preveían:

«a) Adoptar, lo antes posible y mediante procedimiento de urgencia, medidas provisionales para corregir la infracción o para impedir que se causen otros perjuicios a los intereses afectados, incluidas las medidas destinadas a suspender o a hacer que se suspenda el procedimiento de adjudicación del contrato público en cuestión o la ejecución de cualquier decisión adoptada por el poder adjudicador. 
b) Anular o hacer que se anulen las decisiones ilegales, incluida la supresión de las características técnicas, económicas o financieras discriminatorias contenidas en los documentos de licitación, en los pliegos de condiciones o en cualquier otro documento relacionado con el procedimiento de adjudicación del contrato en cuestión.»

Como se puede observar, el objeto de la Directiva no era otro que tratar de reforzar los mecanismos de aplicación efectiva de la normativa comunitaria en materia de adjudicación de contratos, en la fase en la que las infracciones aún podían corregirse de la manera más rápida y eficaz posible. Y todo ello de acuerdo a la interpretación que sustentaba la STJUE, Sala Sexta, de 28 de octubre de 1999, cuando declaró que

"Los Estados miembros están obligados a establecer, en todos los casos, independientemente de la posibilidad de obtener una indemnización por daños y perjuicios, un procedimiento de recurso que permita al demandante obtener, si concurren los correspondientes requisitos, la anulación de la decisión del órgano de contratación anterior a la celebración de contrato por la que resuelve con qué licitador en dicho procedimiento celebrará el contrato.»

Incomprensible, nuestro país continuó ajeno estas directrices. El Preámbulo de la Ley 13/1995, de 18 de mayo, de Contratos de las Administraciones Públicas, fundamentaba la negativa a incorporar las Directivas comunitarias justificando que el sistema garantista en la materia, presuntamente, venía siendo cubierto por el ordenamiento jurídico español desde tiempo atrás ${ }^{4}$. Pero este argumento fue difícil de sustentar durante mucho tiempo y el posterior Real Decreto Legislativo 2/2000, de 16 de junio, mediante el que se aprobó el Texto Refundido de la Ley de Contratos de la Administraciones Públicas, hubo de ampliar la aplicación de gran parte de los preceptos que sujetaban la contratación pública a los entes y empresas vinculados a la Administración, que anteriormente escapaban a dicha normativa. La regulación introdujo también la posibilidad de adoptar, eventualmente, la suspensión del procedimiento de adjudicación como medida provisional en aquellos casos de impugnación con menoscabo de terceros.

Sin embargo y pese a la especialidad de la materia, la justificación contenida en el propio Preámbulo de la Ley de 1995 continuó operando en base al régimen general de recursos establecidos en la entonces vigente Ley 30/1992, de 26 de diciembre, de Régimen Jurídico de las Administraciones Públicas y del Procedimiento Administrativo Común. Como era de esperar, la Comisión Europea entendió que este

${ }^{4}$ Vid. Exposición de Motivos de la Ley 13/1995, de 18 de mayo, de Contratos de las Administraciones Públicas. BOE de 19 de mayo de 1995. 
sistema se antojaba a todas luces insuficiente con sus directrices y en el año 2001 intimó la articulación de medidas que ajustasen realmente el ordenamiento español a la jurisprudencia comunitaria. El resultado fue nulo y finalmente el Tribunal de Justicia de la Unión Europea, en sus SSTJUE de 15 de mayo y de 16 de octubre de 2003, hubo de condenar al Reino de España por incumplimiento de la obligación de extender el sistema de recursos contractuales promovido desde el Derecho comunitario.

Obligado a ello, el artículo 37 de la Ley 30/2007, de 30 de octubre, de Contratos del Sector Público (LCSP), hubo de incorporar un nuevo recurso especial en materia de contratación, si bien de ámbito objetivo y limitado tan sólo a la impugnación de decisiones adoptadas en fase de preparación y adjudicación de ciertos contratos. El recuso fue vivamente criticado por la doctrina, a la que no acababa de encajar su configuración, pues precisamente el marcado carácter obligatorio del que se había dotado como presupuesto procesal para acudir a la vía jurisdiccional, casaba mal con el ordenamiento administrativo patrio ${ }^{5}$. Además, este cuerpo extraño denominado recurso especial en materia de contratación no preveía ciertos plazos, como el de notificación de la adjudicación al resto de licitadores o el intermedio entre la efectiva adjudicación y la celebración del contrato, ni tampoco contemplaba la resolución el recurso a un órgano independiente del órgano de contratación.

Una vez más, España quedaba rezagada, pues ya por entonces la Unión Europea había dado otro paso en sus políticas de refuerzo de las garantías en materia de contratación pública, adoptando sendas normas de índole eminentemente sustantiva: las Directivas 2004/17/ CE y 2004/18/CE del Parlamento Europeo y del Consejo, de 31 de marzo de 2004. Ambas establecieron una serie de medidas en la contratación pública relacionada con los sectores del agua, la energía, los transportes y los servicios postales, así como en la coordinación de los procedimientos de adjudicación pública de obras, suministro y servicios, respectivamente, haciendo aún más patente la necesidad de mejorar la eficacia de los procedimientos de recurso en materia de adjudicación de contratos públicos.

${ }^{5}$ Vid. Dictamen del Consejo de Estado 499/2010, de 29 de abril, en relación con el Anteproyecto de Ley de modificación de las Leyes 30/2007, de 30 octubre, de contratos del sector público y $31 / 2007$, de 30 octubre, sobre procedimientos de contratación en los sectores del agua, la energía, los transportes y los servicios postales para su adaptación a la normativa comunitaria. 
Y esta fue precisamente la medida que se trató de paliar con la Directiva 2007/66/CE del Parlamento Europeo y del Consejo, de 11 de diciembre, mediante la que se modificaron sustancialmente las normas procesales o de recursos, que en esencia reflejaban la citada Directiva 89/665/CEE, así como la Directiva 92/13/CEE del Consejo, de 25 de febrero de 1992, relativa a la coordinación de las disposiciones legales, reglamentarias y administrativas referentes a la aplicación de las normas comunitarias en los procedimientos de formalización de contratos de las entidades que operen en los sectores del agua, la energía, los transportes y las telecomunicaciones.

La reforma introdujo precisamente la necesidad de establecer un plazo suspensivo mínimo que garantizara la tutela judicial efectiva de los licitadores no excluidos definitivamente el procedimiento, hasta que el órgano que examinara el recurso tomara una decisión sobre la solicitud de las medidas provisionales o sobre el fondo del recurso. Pero, como hemos visto, la modificación operada con la LCSP, imposibilitaba que los licitadores excluidos del procedimiento de adjudicación pudieran interponer eficazmente un recurso contra el acto de exclusión y, en su caso, aspirar a ser adjudicatario antes de la efectiva celebración del contrato.

Como era previsible, la STJUE, de 3 de abril de 2008, vino a condenar nuevamente al Reino de España, en tanto su ordenamiento no permitía garantizar una protección jurídica completa de los licitadores antes de la celebración del contrato, tal y como establecía el citado artículo 2.1 de la Directiva 89/665/CEE, en tanto no preveía

«Un plazo obligatorio para que la entidad adjudicadora notifique la decisión de adjudicación de un contrato a todos los licitadores y al no prever un plazo de espera obligatorio entre la adjudicación de un contrato y su celebración.»

El Estado español hubo de incorporar entonces el contenido de la Directiva 2007/66/CE a la LCSP y a la Ley 31/2007, de 30 de octubre, sobre Procedimientos de Contratación en los Sectores del Agua, la Energía, los Transportes y los Servicios Postales (LPCS), con la finalidad de establecer procedimientos ágiles en los que las decisiones resolutorias pudiera adoptarse en el tiempo más breve posible sin dejar de atender a la garantía de los derechos de los interesados.

Y, como se apuntó anteriormente, a este fin fue encomendada la Ley 34/2010, de 5 de agosto, por la que se modificaba el régimen contractual anterior, instaurando un nuevo Libro VI en la LCSP, en puridad artículos 310 a 320, para incorporar un recurso especial en materia de contratación a fin de regular, entre otros aspectos, los actos 
recurribles, la legitimación activa, los plazos de tramitación y el órgano competente para resolver sobre la impugnación contractual ${ }^{6}$. A su vez, esta reforma se completaba en lo referente a determinados sectores de contratación con los artículos 101 a 111, de la LPCS.

Con todo, sin duda la novedad más importe fue la creación de un órgano administrativo altamente especializado, no sujeto a jerarquización orgánica e independiente respecto de la Administración pública correspondiente, cuyas resoluciones, en virtud de los artículos 21.1 de la LCPS y 108 de la LPCS eventualmente podían ser recurridas en sede Contencioso-administrativa. En el ámbito de la Administración General del Estado y adscrito al Ministerio de Hacienda, el artículo 311.1 de LCSP reguló el Tribunal Administrativo Central de Recursos Contractuales, estableciéndose en los siguientes apartados del mismo precepto legal la posibilidad de creación de órganos similares por las Comunidades Autónomas y las Corporaciones Locales, en función de la distribución territorial de competencias, así como por aquellos poderes adjudicadores que no tuvieran la consideración de Administraciones públicas.

El párrafo cuarto del artículo 311.2 de LCSP determinaba la obligatoriedad de suscribir un convenio con la Administración General del Estado, para aquellas Comunidades Autónomas que decidieron no crear este tipo de órganos. En la actualidad, están acogidas a este convenio el Principado de Asturias, Islas Baleares, Cantabria, CastillaLa Mancha, Ciudad de Ceuta, Galicia, La Rioja, Ciudad de Melilla, Región de Murcia y la Comunidad Valenciana.

Para todas ellas el Tribunal Administrativo Central de Recursos Contractuales resulta competente para resolver los eventuales recursos que pudieran interponerse, tanto en su ámbito competencial como en el del resto de Administraciones públicas y entes locales sujetos territorialmente a las mismas.

Por el contrario, hubo una serie de Comunidades Autónomas que prefirieron crear, con las particularidades que se explicitan a continuación, sus propios órganos de resolución de conflictos en materia de contratos públicos.

${ }^{6}$ A juicio del Consejo de Estado la inclusión del citado Libro VI, denominado «Régimen especial de revisión de decisiones en materia de contratación y medios alternativos de resolución de conflictos», era del todo inadecuado o, al menos, asistemático en cuanto a su estructura, al no referir también la cuestión de nulidad ni el control de la propia contratación pública. Vid. Dictamen del Consejo de Estado 499/2010, de 29 de abril, en relación al Anteproyecto de Ley de modificación de la normativa contractual. 
La más madrugadora de todas ellas fue la Comunidad de Madrid, que a finales de 2010 creó su propio Tribunal Administrativo de Contratación Pública ${ }^{7}$, si bien es cierto que por las mismas fechas el País Vasco ya había articulado la posibilidad de un órgano administrativo unipersonal especializado en materia de recursos contractuales, dentro de su ámbito territorial ${ }^{8}$.

En el año 2011 la Comunidad Autónoma de Cataluña optó también por esta segunda posibilidad, aprobando la creación de un órgano unipersonal y especializado en materia de recursos contractuales que, no obstante, al poco tiempo y dado el volumen y la complejidad de los asuntos tramitados, acabó transformándose en órgano colegiado, dando forma al actual Tribunal Catalán de Contratos del Sector Público ${ }^{9}$. Meses antes había sido creado el Tribunal Administrativo de Contratos Públicos de Aragón y, ya a finales de año y mediante disposición reglamentaria, fue articulado un Tribunal de Recursos Contractuales en el seno de la Junta de Andalucía ${ }^{10}$.

En 2012 fue creado el Tribunal Administrativo de Recursos Contractuales de Castilla y León, adscrito al Consejo Consultivo de la misma Comunidad Autónoma ${ }^{11}$. Y en 2013 se creó el Tribunal Administrativo de Contratos Públicos de Navarra ${ }^{12}$.

${ }^{7}$ Vid. Artículo 3 de la Ley 9/2010, de 23 de diciembre, de Medidas Fiscales, Administrativas y de Racionalización del Sector Público de la Comunidad de Madrid. Tras la supresión del Consejo Consultivo de la Comunidad de Madrid, se le atribuyeron competencias en materia de transparencia, acceso a la información pública y buen gobierno. Vid. Disposición Transitoria Segunda de la Ley 5/2016, de 22 de julio, por la que se modificó la Regulación del Tribunal Administrativo de Contratación Pública de la Comunidad de Madrid.

${ }^{8}$ Vid. Disposición Adicional Octava de la Ley 5/2010, de 23 de diciembre, de Presupuestos del País Vasco.

${ }^{9}$ Vid. Disposición Adicional Cuarta de la Ley 7/2011, de 27 de julio, de Medidas Fiscales y Financieras de Cataluña por la que se creó el Órgano Administrativo de Recursos Contractuales de Cataluña, así como Decreto 221/2013, de 3 de septiembre, por el que se regula el Tribunal Catalán de Contratos del Sector Público y aprueba su organización y su funcionamiento.

${ }^{10}$ Vid. Artículos 17-22 de la Ley 3/2011, de 24 de febrero, de medidas en materia de Contratos del Sector Público de Aragón. Decreto 332/2011, de 2 de noviembre, por el que se crea el Tribunal Administrativo de Recursos Contractuales de la Junta de Andalucía.

${ }^{11}$ Vid. Artículos 58 a 64 de la Ley 1/2012, de 28 de febrero, de medidas Tributarias, Administrativas y Financieras de Castilla y León.

${ }^{12}$ El caso de Navarra es particularmente especial, dado que la Ley Orgánica 13/1982, de 10 de agosto, de Reintegración y Amejoramiento de su Régimen Foral, reconoce su competencia exclusiva en materia contractual. La creación de un órgano con independencia funcional, adscrito orgánicamente a la Junta de Contratación Pública, se produjo a través del Artículo 38 de la Ley Foral 3/2013, de 25 de febrero, 
Finalmente, el año 2015 conoció el novísimo ejercicio de la función resolutoria a través de dos órganos de este tipo. La Comunidad Autónoma de Canarias estableció, mediante disposición reglamentaria, un órgano unipersonal de carácter administrativo especializado en materia de revisión de procedimientos de contratación, que no obstante fue denominado Tribunal Administrativo de Contratos Públicos de la Comunidad Autónoma de Canarias ${ }^{13}$; mientras que a través de una Disposición Final insertada en la normativa ordenadora de su función pública la Comunidad Autónoma de Extremadura atribuyó las mismas funciones al Tribunal de Administrativo de Recursos Contractuales de Extremadura, inserto como en el caso de Castilla y León en su correspondiente Consejo Consultivo ${ }^{14}$.

Hasta el cierre del presente trabajo, estos han sido los órganos de resolución de conflictos contractuales creados en el ámbito territorial de las Comunidades Autónomas. Todos ellos se han atribuido competencias en relación con el conocimiento y resolución de los recursos especiales en materia de contratación, y de las reclamaciones a que se refieren los artículos 40 del TRLCSP y 101 de la LPCS, con la adopción de decisiones sobre la solicitud de medidas provisionales a que se refieren los artículos 43 del TRLCSP y 103 de la LPCS, y con la tramitación del procedimiento y la resolución de las cuestiones de nulidad contractual en los supuestos especiales establecidos en los artículos 37 del TRLCSP y 109 de la LPCS.

No obstante, pese al efecto espejo y similitud de funciones que, en el conjunto de criterios, justificaron su creación, las normativas que regulan estos órganos presentan algunas peculiaridades propias que a continuación pasamos a exponer.

por el que se añadió un nuevo artículo 208 bis a la Ley Foral 6/2006, de 9 de junio, de Contratos Públicos de Navarra.

${ }^{13}$ Vid. Decreto 10/2015, de 12 de febrero, por el que se crea el Tribunal Administrativo de Contratos Públicos de la Comunidad Autónoma de Canarias.

${ }^{14}$ Vid. Disposición Adicional Segunda de la Ley 13/2015, de 8 de abril, de Función Pública de Extremadura. Su cuando menos curiosa inclusión en esta normativa obedece a que una primera propuesta de creación, promovida por el Grupo Parlamentario Popular de la Asamblea de Extremadura y que debía haber motivado una enmienda de modificación de la Disposición Adicional al Proyecto de Ley de Medidas Tributarias, Administrativas y Financieras de la Comunidad Autónoma, finalmente no llegó a prosperar por razones políticas y el Tribunal Administrativo de Recursos Contractuales de Extremadura hubo de retrasar dos meses su efectiva puesta en marcha. BOAE núm. 170, de 28 de enero de 2015 y núm. 754, de 13 de marzo de 2015, respectivamente, así como DOE núm. 107, de 5 de junio de 2015, en el que se da publicidad al Acuerdo del Consejo Consultivo de Extremadura, de 14 de mayo de 2015, sobre la constitución del Tribunal Administrativo de Recursos Contractuales de Extremadura. 


\section{COMPOSICIÓN Y CARÁCTER DE LOS ÓRGANOS DE RESOLUCIÓN DE CONFLICTOS CONTRACTUALES}

En primer lugar, hay que señalar que las Comunidades Autónomas que finalmente optaron por la creación ad hoc de este tipo de órganos, hubieron de decidir entre una configuración de carácter unipersonal $\mathrm{u}$ otra de tipo colegiado. Respecto al primer caso, en la actualidad tan sólo perviven dos de ellos: el Órgano Administrativo de Recursos Contractuales de la Comunidad Autónoma de Euskadi ${ }^{15}$ y el Tribunal Administrativo de Contratos Públicos de la Comunidad Autónoma de Canarias, que pese a su denominación está compuesto por un único titular, previéndose no obstante que el Consejo de Gobierno acuerde su transformación en órgano colegiado, para el caso en el que el volumen y especificidad de los asuntos sometidos a su conocimiento así lo aconseje ${ }^{16}$.

En ambos órganos pervive también una suerte de jurisdicción compartida con los entes locales vinculados a su territorio. El apartado segundo de la Disposición Adicional Octava de la Ley 5/2010, de 23 de diciembre, de Presupuestos de Euskadi faculta a los municipios de más de cincuenta mil habitantes para crear su propio órgano competente en relación con la resolución de recursos contractuales del ámbito local y sector público respectivo. Por su parte, el artículo 2.3 del Decreto 10/2015, de 12 de febrero, por el que se creó el Tribunal Administrativo de Contratos Públicos de la Comunidad Autónoma de Canarias, atribuye similares competencias en el ámbito de las administraciones locales y universidades insulares, de tal modo que el Cabildo de Gran Canarias recientemente creó un tribunal vinculado al ámbito del sector público que le es propio $^{17}$.

En Cataluña, el apartado segundo de la Disposición Adicional Cuarta de la Ley 7/2011, de 27 de julio, de medidas Fiscales y Financieras de la Comunidad Autónoma, mediante la que se estableció el Órgano Administrativo de Recursos Contractuales de Cataluña, permitía igualmente a los municipios de más de cincuenta mil habitantes articular un órgano de este tipo con competencia restringida para

${ }^{15}$ El Apartado Séptimo de la Disposición Adicional Octava de la Ley 5/2010, de 23 de diciembre, de Presupuestos de Euskadi, dispuso su creación unipersonal, sin perjuicio de posibilitar el incremento de sus miembros en el futuro. El nombramiento de su titular se produjo mediante 103/2011, de 31 de mayo. Vid. BOPV núm. 105, de 3 de junio de 2011.

${ }^{16}$ Vid. Artículos 1 y 4.1. del Decreto 10/2015, de 12 de febrero, por el que se crea el Tribunal Administrativo de Contratos Públicos de la Comunidad Autónoma de Canarias.

${ }^{17}$ Vid. BOC núm. 39, de 26 de febrero de 2016. 
resolver los recursos de su ámbito local, pero esta posibilidad fue anulada tres años más tarde ${ }^{18}$. La Comunidad Autónoma de Cataluña también se decidió en primera instancia por la creación de un órgano unipersonal, previendo no obstante su transformación colegiada en aras a aligerar la carga de los asuntos que eventualmente le fueran consultados ${ }^{19}$. Pero, como cabe colegir, en muy escaso tiempo fueron articuladas medidas de eficacia en este ámbito y el Decreto 221/2013, de 3 de septiembre, mediante el que se regulaba la creación del Tribunal Catalán de Contratos del Sector Público, además de su organización y funcionamiento, estableció la colegiación acorde con su nueva denominación. En la actualidad está compuesto por un Presidente y dos vocales cuyo número, no obstante, también podría incrementarse en un futuro ${ }^{20}$.

En la Comunidad Autónoma de Andalucía el Proyecto de Decreto que preveía su creación barajó de inicio una composición colegiada, pero en última instancia y amparándose en razones de austeridad, se introdujo un carácter unipersonal del órgano que llegó a confundir de entrada al resto de operadores jurídicos. La extemporaneidad y lo escasamente fundada de la decisión provocó no pocas críticas del Consejo Consultivo de Andalucía, que su Dictamen 681/2011, de 18 de octubre, subrayó precisamente el menoscabo que su desconocimiento suponía respecto al derecho de audiencia y eventuales alegaciones de los interesados en la aprobación del reglamento.

Además, el Consejo Consultivo de Andalucía entendió que resultaba inadecuado denominar tribunal a un órgano formado por un solo miembro, cosa que como hemos visto no supuso mayor obstáculo en la creación de su homónimo canario. Sin embargo, la Alta Instancia consultiva andaluza razonaba que:

«En la tradición de nuestro país se ha acuñado noción estricta de la palabra "tribunal", que lleva a una distinción entre los órganos unipersonales encargados de la decisión de determinados asuntos y los tribunales. Así en la esfera judicial (Ley Orgánica 6/1985, de 1 de julio, del Poder Judicial y Ley 38/1988, de 28 de diciembre, de Demarcación y de Planta Judicial) se distingue entre Juzgados (órganos unipersonales) y Tribunales (órganos colegiados), otras veces se habla de Jueces y Tribunales, pero en ningún caso se identifican éstos con "tribunales unipersonales". Lo mismo cabe decir en el ámbito de los órganos encargados de resolver las

${ }^{18}$ Vid. Ley 2/2014, de 27 de enero, de Medidas Fiscales, Administrativas y Financieras de Cataluña.

${ }^{19}$ Vid. Apartado 17 de la Disposición Adicional Cuarta de la Ley 7/2011, de 27 de julio, medidas Fiscales y Financieras de la Comunidad Autónoma de Cataluña.

${ }^{20}$ Vid. Artículo 5 del Decreto 221/2013, de 3 de septiembre, mediante el que se regula la creación del Tribunal Catalán de Contratos del Sector Público. 
reclamaciones económico-administrativas, cuya regulación se ha tenido presente, sin duda, al optar por la creación de órganos especializados en materia de recursos contractuales.

En efecto, de la regulación prevista en la Ley 58/2003, de 17 de diciembre, General Tributaria, y en el Reglamento general de desarrollo de dicha Ley en materia de revisión en vía administrativa, aprobado por el Real Decreto 520/2005, de 13 de mayo, resulta una organización compuesta por diversos órganos colegiados (Tribunal Económico-Administrativo Central, tribunales económico-administrativos regionales y locales, salas desconcentradas, y Sala Especial para la Unificación de Doctrina), sin perjuicio de que a efectos de funcionamiento de forma unipersonal se atribuya la consideración de órganos unipersonales a quienes sean designados como tales por acuerdo del presidente del Tribunal Económico-administrativo Central, y a los efectos de resolver cuestiones incidentales o declarativas de la inadmisibilidad y de dictar el acuerdo de archivo de las actuaciones, tanto en el procedimiento general como en el abreviado, los presidentes, vocales y secretarios de cada Tribunal.»

Sin duda, el Ejecutivo andaluz finalmente debió tener en cuenta estas consideraciones y acabó por modificar el artículo 2.1 del Decreto 332/2011, de 2 de noviembre, por el que se creó el Tribunal Administrativo de Recursos Contractuales de la Junta de Andalucía, a fin de contemplar una composición tripartita del órgano, que está formado desde entonces por una presidencia y dos vocalías ${ }^{21}$.

Una estructura similar a la anterior presentan también el Tribunal Administrativo de Contratos Públicos de Navarra, compuesto de un Presidente y dos vocales además del secretario de la Junta de Contratación Pública ${ }^{22}$, y el Tribunal Administrativo de Contratos Públicos de Aragón, compuesto por un Presidente y dos vocales, además del secretario de su Junta Consultiva de Contratación Administrativa, con voz y sin voto ${ }^{23}$. Con dos miembros más cuenta el Tribunal Administrativo de Contratación Pública de la Comunidad de Madrid, pues

${ }^{21}$ Vid. Artículo 2.1. Decreto 332/2011, de 2 de noviembre, por el que se crea el Tribunal Administrativo de Recursos Contractuales de la Junta de Andalucía. El Decreto 120/2014, de 1 de agosto, introdujo la posibilidad, para el caso de que se produjera un incremento del número de asuntos, añadir un número indeterminado de vocales cuya decisión competía al Consejo de Gobierno. El órgano es además asistido por un secretario, sin voz ni voto, que deberá ser un funcionario de la Administración autonómica con licenciatura en Derecho y antigüedad superior a tres años.

${ }^{22}$ Vid. Apartado segundo del artículo 208 bis de la Ley Foral 6/2006, de 9 de junio, de Contratos Públicos de Navarra, en la modificación introducida por el artículo 38 Ley Foral 3/2013, de 25 de febrero.

${ }^{23}$ Vid. Artículos 18 y 20 de la Ley 3/2011, de 24 de febrero, de medidas en materia de Contratos del Sector Público de Aragón. 
además del Presidente está formado por cuatro vocales, así como un secretario funcionario de carrera con voz pero sin voto ${ }^{24}$.

Apuntado lo anterior, merece detenernos a comentar siquiera someramente dos casos significativos en la configuración de este tipo de órganos, como son los de Castilla y León y Extremadura. Efectivamente, tal y como se dijo, la Comunidad Autónoma de Castilla y León optó por atribuir las competencias en materia de resolución de conflictos contractuales a su ya creado y plenamente operativo Consejo Consultivo, decisión a la que también se sumó la Comunidad Autónoma de Extremadura respecto a su homónima instancia consultiva.

A nuestro juicio, la medida resultaba acertada por diversas razones: se ajustaba a los principios de austeridad y eficacia que deben presidir la actuación de las Administraciones públicas, a la par que se proveía de un personal altamente cualificado y de reconocido prestigio en el ámbito jurídico, y se garantizaba la tan reiterada independencia orgánica y funcional, así como la objetividad exigida por la jurisprudencia comunitaria, pues no en vano y en el caso del Consejo Consultivo de Extremadura, su estatus institucional venía avalado por la relevancia estatutaria que lo configuraba como el Órgano Consultivo Superior de las Administraciones de la Comunidad Autónoma de Extremadura ${ }^{25}$.

Sin embargo e incomprensiblemente, al poco tiempo de su puesta en funcionamiento la discrecionalidad política, avalada por algún que otro sector de la doctrina ${ }^{26}$, vino a sustituir aquella estructura por

\footnotetext{
${ }^{24}$ Vid. Apartado segundo del artículo 3.1. de la Ley 5/2016, de 22 de julio, por la que se modificó la Ley 9/2010, de 23 de diciembre, de Medidas Fiscales, Administrativas y Racionalización del Sector Público.

${ }^{25}$ Vid. Artículo 45 de la Ley Orgánica 1/2011, de 28 de febrero, de reforma del Estatuto de Autonomía de la Comunidad Autónoma de Extremadura.

${ }^{26}$ Vid. Por todos, el informe de la Comisión para la Reforma de las Administraciones Públicas (CORA), en el que se banalizaba con la función de los órganos consultivos, proponiendo que las normas autonómicas elevasen la cuantía mínima necesaria para poder solicitar el dictamen del respectivo órgano consultivo en aquellos casos que se dilucidaba la responsabilidad patrimonial de la Administración, fijándose el límite en los 50.000 euros, para que fuera el Consejo de Estado el que asumiese la resolución de dichos expedientes y así ahorrar a la Administración consultante el «exorbitante» sostenimiento del órgano autonómico. Pese a lo escasamente sostenible de su propuesta, el eco mediático de la misma propició la supresión de alguno de estos órganos. Http://transparencia.gob.es/transparencia/dam/ jcr:b1c69477-9882-41a5-9f6d-5cbb46fa12b4/reforma-AAPP.PDF. Coadyuvó así mismo a la supresión de la Alta Instancia Consultiva extremeña el premiado ensayo del profesor Muñoz Machado, en el que se achacaba la doliente crisis institucional, a nuestro juicio un tanto precipitadamente, a la «soberbia de las Comunidades Autónomas» que querrían equipararse a las instituciones estatales careciendo, entre otras cuestiones, de su posición, responsabilidad o tradición, y ejemplarizaba dichos ma-
} 
otra similar, aunque no idéntica, residenciada en la Comisión Jurídica que fue creada a tales efectos ${ }^{27}$. El nuevo órgano se estructuró así desde sus inicios de acuerdo con una naturaleza dual: consultiva y resolutoria. La primera de ellas fue reconocida por el propio Consejo de Estado, para el que la Comisión Jurídica de Extremadura, en este punto, era «el órgano llamado a sustituir al extinto Consejo Consultivo autonómico ${ }^{28}$. Aunque ello sin perjuicio de las competencias previstas en el artículo 45.2 del Estatuto de Autonomía ${ }^{29}$, así como en la posibilidad de efectuar consultas de carácter facultativo que contemplaba el artículo 14 de la Ley 16/2001, de 14 de diciembre, del Consejo Consultivo de Extremadura. Por el contrario, el Consejo de Estado aludía a la expresa voluntad del legislador extremeño de mantener aquellas otras competencias que, sin resultar materia estatutaria, venían siendo atribuidas a la extinta instancia consultiva. Además, la profesionalidad y especialidad de sus miembros quedó sobradamente acreditada $^{30}$, salvaguardando una de las exigencias que reiteradamente venían haciéndose desde Bruselas y que, al menos en parte, la an-

les en la figura de sus respectivos Consejos Consultivos. MuÑoz Machado, Santiago. Informe sobre España. Repensar el Estado o destruirlo. Editorial Crítica. Barcelona, 2012. Págs. 188-191.

${ }^{27}$ Vid. Ley 19/2015, de 23 de diciembre, por la que se deroga la Ley 16/2001, de 14 de diciembre de, reguladora del Consejo Consultivo de Extremadura. Las funciones del Tribunal Administrativo de Recursos Contractuales de Extremadura que mediante la Disposición Final Segunda de la Ley 13/2015, de 8 de abril, habían sido atribuidas al Consejo Consultivo, pasaron a ser desempeñadas por la recién creada Comisión Jurídica en virtud del Apartado Sexto de aquella Ley.

${ }^{28}$ Vid. Dictamen del Consejo de Estado 64/2016, de 31 de marzo.

${ }^{29}$ En este sentido, el artículo 45.2 de la Ley Orgánica 1/2011, de 28 de enero, de reforma del Estatuto de Autonomía de Extremadura, establece que «El Consejo dictaminará sobre la adecuación a la Constitución, al presente Estatuto y al ordenamiento jurídico, de los anteproyectos de reforma estatutaria, de los proyectos de ley, de anteproyectos de otras normas con rango de ley, de la interposición o mantenimiento de recursos y acciones ante el Pleno del Tribunal Constitucional y su personación en ellos, y de los demás supuestos previstos en este Estatuto. Igualmente dictaminará, en los casos que establezca su ley constitutiva, sobre la legalidad de las disposiciones generales y actos de las instituciones autonómicas, de la administración regional, de las universidades públicas y de las corporaciones locales de Extremadura y de los organismo y entes de derecho público dependientes o vinculados a ellas.»

${ }^{30}$ Efectivamente, el Apartado Séptimo de la Ley 19/2015, de 23 de diciembre, resolvió que los cinco miembros de este nuevo órgano debían ser nombrados entre funcionarios de carrera de cualquier Administración pública extremeña, con la categoría de letrado o técnicos superiores de especialidad jurídica y más de diez años de servicio activo. Y el artículo 49.1 del Decreto 99/2009, de 8 de mayo, fue más allá exigiendo la acreditación de cualificaciones jurídicas y profesionales en el ámbito de atribución sobre el que deberían conocer y, especialmente, en materia de contratación del sector público. Este último requisito se incrementaba para el caso de la presidencia del órgano, a cuyo cargo el siguiente artículo 50.1 exigía un mínimo de cinco años de experiencia en la materia. 
terior legislación no había previsto para el caso de la figura del consejero permanente eventualmente lego en Derecho ${ }^{31}$.

Este era un obstáculo complicado de justificar en aras de la cada vez más exigente especialidad requerida a este tipo de órganos y que, pese a llevar trazas de convertirse en un problema irresoluto, tal y como fue reconocido en su momento ${ }^{32}$, acabó por ser solucionado con la nueva configuración del órgano extremeño. Por el contrario, continuó perviviendo en su homónimo castellano y, puesto que su normativa reguladora reproducía esta misma figura del consejero sin formación jurídica, muy pronto propició que algunos autores se mostraran muy críticos con las resoluciones emanadas del mismo, minusvalorando, según Fuentes López, «el valor adicional que puede darse a este tipo de resoluciones más allá del ser opiniones de un órgano que no cumple, en modo alguno, con los parámetros establecidos por la normativa estatal y de la Unión Europea y, en consecuencia, con las garantías que con esas previsiones se persiguen ${ }^{33}$.

Y es que, efectivamente, la citada Directiva 2007/66/CE del Parlamento Europeo y del Consejo, de 11 de diciembre, había exigido del legislador nacional dos requisitos esenciales que habría de tener en cuenta a la hora de crear este tipo de órganos en sede administrativa: la independencia y la especialización; de modo que:

«El nombramiento de los miembros de esta instancia independiente y la terminación de su mandato estarán sujetos a las mismas condiciones aplicables a los jueces en lo relativo a la autoridad responsable de su nombramiento, la duración de su mandato y su revocabilidad. Como

${ }^{31}$ Artículo 4.3 de la citada Ley del Consejo Consultivo de Extremadura preveía esta figura, de modo que «los Consejeros permanentes serán aquellas personas que, residiendo en la Comunidad Autónoma de Extremadura y gozando de la condición política de extremeños, hayan desempeñado algunos de los cargos que a continuación se relacionan durante, al menos, un mandato completo: a) Presidentes del Gobierno, del Congreso de los Diputados, del Senado y del Tribunal Supremo; y b) Presidentes de la Comunidad Autónoma de Extremadura, de la Asamblea de Extremadura y del Tribunal Superior de Justicia de Extremadura». Hay que decir que a lo largo de su trayectoria formaron parte del extinto Consejo Consultivo tres consejeros permanentes y solamente uno de ellos no era jurista, si bien ya se había extinguido su mandato al tiempo de ponerse en funcionamiento el referido Tribunal Administrativo de Recursos Contractuales.

${ }^{32}$ Jover Lorente, Felipe Anastasio y otros. «El Consejo Consultivo de Extremadura como Tribunal Administrativo de Recursos Contractuales de la Comunidad Autónoma: regulación y doctrina más destacada». Revista Española de la Función Consultiva, núm. 23. Consejo Jurídico Consultivo de la Comunidad Valenciana, 2015; pág. 2.

${ }^{33}$ FuERTES LÓPEZ, Francisco Javier. «Sobre los órganos de resolución de conflictos contractuales y el valor de sus resoluciones». Aranzadi Doctrinal, núm. 4. Editorial Aranzadi. Cizur Menor, 2015; pág. 43. 
mínimo, el presidente de esta instancia independiente deberá poseer las mismas cualificaciones jurídicas y profesionales que un juez.»

Como se puede apreciar, la independencia y la especialidad son los dos principales requisitos que configuran el carácter jurisdiccional que, tanto la normativa como la jurisprudencia reconocen a los órganos encargados de resolver las impugnaciones en materia de contratación pública.

En cuanto al primero de los requisitos, resulta claro que deberán ejercer sus funciones con plena autonomía, sin estar sometidos a vínculo jerárquico o de subordinación alguno respecto a terceros y sin recibir órdenes ni instrucciones de origen alguno. Esto les protege de injerencias o presiones externas que puedan hacer peligrar la independencia de juicio de sus miembros, en la expresión utilizada por la citada Sentencia del Tribunal Supremo, de 5 de noviembre de 2014, respecto a su homónimo catalán, ya que:

«Ningún otro interés público se podría anteponer al ligado de esta presunción de imparcialidad, sin cuya garantía la contratación de ámbito comunitario sería insostenible y comportaría a los estatutos incumplidores muy graves consecuencias.»

$\mathrm{Al}$ respecto, debe decirse que todas las normativas que regulan este tipo de órganos mencionan expresamente la falta de sometimiento a directrices del poder adjudicador, ni a ningún tipo de jerarquía orgánica o funcional en la Administración pública a la que son adscritos. En este sentido, lo más común es que sean adscritos, sin llegar a participar de su estructura orgánica y con plena independencia funcional, al departamento competente en materia de contratación pública de la Administración autonómica respectiva. No obstante, existen dos excepciones, pues como hemos visto, en el caso de Castilla y León el tribunal se inserta dentro de su Consejo Consultivo y, en el caso de Extremadura dentro de su Comisión Jurídica que, a su vez, está adscrita a la Abogacía general del Ejecutivo autonómico.

Por otro lado, la independencia del presidente y los miembros de los tribunales de resolución de conflictos contractuales vendría avalada así mismo por la garantía de permanencia en su función que les confiere la normativa y por el régimen de incompatibilidades, asimilándola a la de los altos cargos y miembros de los respectivos consejos de gobiernos autonómicos. En cuanto a lo primero, por lo general el nombramiento conlleva el desempeño por un tiempo de seis años, cinco en los casos de Andalucía, Canaria, Cataluña y Extremadura, renovable una única vez por igual período, pudiendo únicamente ser removidos o cesados en los casos en los que concurra alguna de las 
circunstancias legalmente previstas. Por su parte, el desempeño en régimen de dedicación exclusiva, resulta un medio de garantizar, además de su independencia funcional, la imparcialidad y total objetividad de sus resoluciones.

La Sentencia Tribunal Supremo de 23 de octubre de 2014, extendió la presunción de imparcialidad de estos órganos a la cualificada presunción de legalidad de sus resoluciones, por lo que el requisito de especialidad está estrechamente vinculado al mismo. En este sentido, es de subrayar que la mayoría de normativas garantizan que las vocalías estén cubiertas por funcionarios de carrera de la Administración autonómica de que se trate, que acrediten el desempeño de más de diez años en el ámbito del Derecho Administrativo relacionado con la contratación pública ${ }^{34}$.

En el caso del miembro que vaya a ocupar la presidencia, la exigencia de experiencia se eleva a quince años, igualmente vinculada al área de la contratación pública. Esto último, que no resulta preceptivo en el caso de Euskadi y Andalucía en los que tan sólo se aconseja la especialización contractual, ni siquiera se menciona en el caso del presidente del Tribunal Administrativo de Recursos Contractuales de Castilla y León cuya figura, como se ha apuntado, recae en el presidente del Consejo Consultivo de aquella Comunidad Autónoma y cuya normativa, en el presente caso, tan sólo previene «diez años de dedicación a función o actividad profesional de contenido jurídico ${ }^{35}$.

La cuestión no es baladí, puesto que si tenemos en cuenta que, siguiendo a la jurisprudencia, la independencia de sus miembros se fundamenta en estrictos criterios técnicos, no parece que el caso se adecúe a la especial significación o cualificación jurídica que, como hemos visto, exigía la Directiva 2007/66/CE del Parlamento Europeo y del Consejo, de 11 de diciembre. La falta de formación jurídica o, como en este supuesto, de especialización en una materia tan compleja como la contratación pública, desvirtúa por completo el carácter, a

${ }^{34}$ No obstante, en el caso de Aragón, el artículo 18.4 de la Ley 3/2011, de 24 de febrero, de medidas en materia de Contratos del Sector Público de Aragón, exige que al menos uno de los vocales de su tribunal provenga de la Administración Local. Esto también ocurre en el caso de Cataluña, donde uno de los vocales deberá proceder igualmente de la Administración Local, con la salvedad de que le estará vetada la presidencia del órgano. Vid. apartados 3 y 4 del artículo 5 y artículo 6 del Decreto 221/2013, de 3 de septiembre, mediante el que se regula la creación del Tribunal Catalán de Contratos del Sector Público.

${ }^{35}$ Vid. Artículo 7.3 de la Ley 1/2002, de 9 de abril, del Consejo Consultivo de Castilla y León, 
medio camino entre la potestas y la auctoritas, que se presupone a resoluciones ${ }^{36}$.

En cualquier caso y tal como se ha expuesto, la práctica totalidad de los tribunales de recursos contractuales cumplen los requisitos de especialización exigidos por Bruselas, así como los criterios de independencia y objetividad que salvaguardan sus normativas de creación, fundamentado con ello el carácter jurisdiccional que declara la jurisprudencia comunitaria. Efectivamente, pese a que las referidas normativas de constitución establecen expresamente la naturaleza administrativa de este tipo de órganos, la STJEU, Gran Sala, de 6 de octubre de 2016, vino por el contrario a negar el carácter de órgano puramente administrativo en el caso del Tribunal Catalán de Contratos del Sector Público, subrayando precisamente su carácter jurisdiccional en atención a su «origen legal, su permanencia, el carácter obligatorio de su jurisdicción, el carácter contradictorio del procedimiento, la aplicación por parte del órgano de normas jurídicas y su independencia.»

A estos parámetros obedeció la voluntad del legislador tal y como se expresó en los trabajos previos a la aprobación del Anteproyecto de Ley de Contratos del Sector Público, una vez que fue descartada la atribución de competencias a los órganos judiciales. Efectivamente, ante la alternativa de atribuir las competencias a los órganos jurisdiccionales u optar por la creación de órganos ad hoc, se consideró esta última tras concluir que aquellos no podrían responder con agilidad y eficacia a la eventual sobrecarga de impugnaciones del ámbito contractual $^{37}$.

Lo cierto es que el artículo 40.6 del TRLCSP previene expresamente la eventual interposición del recurso especial en materia de contratación. Es decir, frente al imperativo legal previsto en el citado artículo 37 de la CLSP, la normativa vigente posibilita la impugnación ante el tribunal de recursos contractuales competente o, potestativamente, ante el orden contencioso-administrativo. No obstante, esta regulación ha sido criticada al considerar que con ella se introducen dos niveles de impugnación y un grado de parcelación jurídica incomprensible en materia de contratación: uno para el recurso especial instaurado para los contratos sujetos a la categoría indicada en las directivas comunitarias, y otro para el resto de contratos que, salvo

${ }^{36}$ Fuertes LóPez, F. J. «Sobre los órganos de resolución...», Ob. cit; pág. 39.

${ }^{37}$ Pulido Quecedo, Manuel. "El nuevo Tribunal Administrativo Central de recursos contractuales». Actualidad Jurídica Aranzadi, núm. 804. Editorial Aranzadi. Cizur Menor (Navarra), 2010, pág. 250. 
alguna especialidad, están sujetos al régimen general de recursos tramitados por las Administraciones públicas.

Además, como apunta Gracia Romero, ello conlleva aparejado que el licitador sujeto a un contrato vinculado al ámbito de las directivas comunitarias, no podrá elegir entre interponer un recurso ordinario de alzada o reposición u optar por el recurso especial en materia de contratación, sino que siempre habrá de estar obligado a este en sede administrativa ${ }^{38}$. Y por si fuera poco y para el caso que se decidiese acudir a la vía jurisdiccional, la configuración del recurso aparentemente deja abierta una doble y gravosa contradicción de plazos, puesto que en vía administrativa el licitador dispone de quince días hábiles, mientras que en la contenciosa tendría dos meses para interponer el recurso.

Sin embargo, en la práctica ocurre, tal y como argumentaba la referida STJUE, Gran Sala, de 6 de octubre de 2016, que:

«Los licitadores en los procedimientos de adjudicación de contratos públicos no recurren por lo general a la posibilidad de interponer directamente recurso contencioso-administrativo, sin haber presentado previamente un recurso especial.»

Y lo cierto es que, una vez resuelto el recurso en sede del tribunal contractual correspondiente y como también ha encargado de demostrar la experiencia, la litigiosidad en esta materia es ciertamente escasa. Además de la comprensible carga económica que, como señala Moreno Molina, conlleva para los licitadores someterse a la tutela judicial ${ }^{39}$, uno de los motivos de desistimiento son las fundadas resoluciones que emanan de este tipo de órganos, las cuales hacen disminuir ostensiblemente las posibilidades estimatorias del recurrente ante las instancias contenciosas. Es por esto que, al intervenir escasamente el orden contencioso-administrativo en segunda instancia, la jurisprudencia comunitaria considera que es a este tipo de órganos a los que compete velar por la adecuación del Derecho comunitario en materia de contratos públicos, quedando acreditado por tanto, el carácter obligatorio de su jurisdicción.

${ }^{38}$ Gracia ROMERO, Luis. «Las nuevas formas de protección a los licitadores en el ámbito de la contratación administrativa. Referencia al Tribunal Administrativo de Recursos Contractuales de Castilla y León». Revista de la Función Consultiva, núm. 21. Consejo Jurídico Consultivo de la Comunidad Valenciana, 2015; págs. 162-163.

${ }^{39}$ En un estudio con datos aportados por el propio Consejo General del Poder Judicial, se concluyó que la duración media para resolver un procedimiento de este tipo por los Tribunales Superiores de Justicia, era de veintinueve meses. Vid. Moreno Molina, Juan Antonio. La reforma de la Ley de Contratos del Sector Público en materia de recursos. Análisis de la Ley 34/2010, de 5 de agosto. La Ley. Madrid, 2011. 


\section{CONCLUSIONES}

En su aún corto recorrido, los órganos resolutorios de conflictos contractuales han emitido un nada desdeñable acervo de doctrina altamente especializada, en aras a garantizar los principios de transparencia y libre concurrencia en materia de contratos públicos que previenen las normas comunitarias. Sin duda, la reordenación autonómica de las atribuciones referidas en un principio al Tribunal Administrativo Central de Recursos Contractuales, con los requisitos exigidos desde Bruselas en cuanto al carácter de sus miembros, resulta positiva tanto para los licitadores como para los poderes públicos adjudicadores en el ámbito territorial que es propio de las Comunidades Autónomas.

No obstante y teniendo en cuenta la vorágine regulatoria que envuelve la materia, es aún pronto para asegurar si estos objetivos quedarán finalmente cubiertos con las atribuciones de las que fueron dotados estos órganos o si será necesario articular medidas complementarias. En este como en otros casos, se antoja esencial el transcurso de un tiempo prudencial en el que poder valorar en su justa media si esta labor se ajusta a la consecución de las directrices comunitarias y, fundamentalmente, si fue acertado atribuirles las funciones de control cuasijudicial que han sido descritas o si, como desgraciadamente sugiere la experiencia en este campo y se ha encargado de subrayar Pulido Quecedo, acaban por plegarse a las consuetudinarias inercias y perversas prácticas que socavan nuestras administraciones, debiendo ceder finalmente el testigo a los órganos judiciales ${ }^{40}$.

${ }^{40}$ Pulido Quecedo, Manuel. «Competencias y legitimación ante el Tribunal Administrativo Central de Recursos Contractuales (TACRECO): especial consideración de los supuestos de nulidad contractual». Revista de Documentación Administrativa núm. 288. 2010, pág. 68. 
